\title{
NEUROPHYSIOLOGICAL INVESTIGATIONS IN THE COLLICULUS INFERIOR OF RHINOLOPHUS FERRUMEQUINUM
}

\author{
by
}

\author{
GERHARD NEUWEILER \\ Zoophysiologisches Institut der Universität, 74 Tübingen, B.R. Deutschland
}

The horseshoe-bat Rhinolophus ferrumequinum is the best known representative of those bats using constant frequency sounds for echolocation. Schnitzler (1968) has shown, that horseshoe-bats compensate Dopplershifts during flight by lowering the emitted constant frequency so that the heard echofrequency always remains at about $83.4 \mathrm{kHz}$. His results suggest that horseshoe-bats use the constant frequency part of their orientation sounds for detection and measuring of flight velocities by means of Doppler shifts.

The investigation reported here intends to give some clues how constant frequency echoes are processed in the main auditory centre, the colliculus inferior, and how Rhinolophus extracts information for orientation from these echo signals.

From 19 Nembutal-anesthetized horseshoe-bats evoked potential of the colliculus inferior were elicited by pure tones from 10 to $100 \mathrm{kHz}$. The experimental set-up closely follows that used by Grinnell (1963) for similar studies in Myotis. The anesthetized bat was secured to a tapered board and put in an electrically shielded chamber. The room was heated to $36-38^{\circ} \mathrm{C}$. Small Silver-silverchloride electrodes were placed on the collicular surface and the recorded potentials fed into a differential amplifier. The evoked potentials were displayed on a Tektronix 564 storage oscilloscope. By means of a square wave generator, a Wavetek oscillator and an electronic switch pure tone signals were produced with a duration of $30 \mathrm{msec}$ and a rise- and falltime of $0.5 \mathrm{msec}$. The intensity of the tone stimuli was varied by an amplifier and an attenuator over a range of $110 \mathrm{db}$. The sound pressure level was monitored by a calibrated Brüel \& Kjaer microphone. The condenser loudspeaker could be moved in a hemispherical plane, so that tone stimuli could be delivered from any angle within $90^{\circ}$ above, $90^{\circ}$ below, $90^{\circ}$ to the right and to the left of the bat's head.

Typical evoked potentials obtained from the colliculus inferior by pure tone stimulation consist of a fast first peak followed by a more or less prominent second slower one. Auditory thresholds of the horseshoe-bat were determined in the following way: the intensity of a tone stimulus which elicited an evoked potential barely visible above the $5 \mu \mathrm{V}$ noise level was considered as the threshold intensity of a given stimulus. Intensities are measured in $\mathrm{db}\left(\mathrm{re} 0.0002 \mathrm{dyn} / \mathrm{cm}^{2}\right.$ ).

First we measured the directional sensitivity of the colliculus. The bat's head was placed in the centre of the hemisphere and thresholds of the collicular evoked response were determined for $30 \mathrm{kHz}$ stimuli at different stimulus angles. The result contains averaged data from 7 bats. In all cases the stimulus direction of lowest thresholds was about $30^{\circ}$ contralateral to the recorded colliculus and $30^{\circ}$ above horizon and the direction of highest thresholds $60^{\circ}$ ipsilateral and $90^{\circ}$ below horizon. The directionality increases with stimulus frequency. For $30 \mathrm{kHz}$, tones the average threshold difference between angles of minimal and maximal threshold is $32 \mathrm{db}$, for $60 \mathrm{kHz} 41 \mathrm{db}$ and for $83.3 \mathrm{kHz}$ - the approximate heard echo frequency $-54 \mathrm{db}$. For $83.3 \mathrm{kHz}$ stimuli there is a second region of low thresholds $30^{\circ}$ ipsilateral and $30^{\circ}$ above horizon. The steep threshold gradients in relation to stimulus direction is greatly affected by the shape and position of the pinnae. In one case the difference between the direction of lowest and highest threshold was $72 \mathrm{db}$ in normal earposition. When the pinnae of this bat are folded back completely the directional sensivity decreases from $72 \mathrm{db}$ to $38 \mathrm{db}$ of maximal threshold difference. Moreover the pattern of directionality is completely altered. The direction of lowest threshold shifted from $15^{\circ}$ contralateral and $30^{\circ}$ 